\title{
Thermal study: Thermal and acoustic insulation plates
}

\section{Josinete Carvalho Stockli ${ }^{1}$; Jorge de Almeida Brito Júnior² ${ }^{2}$ Charles Gomes Mafra ${ }^{3}$; Antônio Estalislau Sanches ${ }^{4}$}

\author{
1,3,4 Universidade Nilton Lins - Parque das Laranjeiras - Av. Prof. Nilton Lins, 3259 - Flores, Manaus - Amazonas CEP: 69058-030 \\ ${ }^{2}$ Instituto de Tecnologia Galileo da Amazônia (ITEGAM) - Av. Joaquim Nabuco, 1950, Centro. Manaus - Amazonas CEP: 69020-030
}

Email: netty_23@hotmail.com,jorgebritojr@gmail.com,mafra.niltonlins@gmail.com,novo.sacnhes@gmail.com.

Received: October $02^{\text {th }}, 2017$.

Accepted:. October $10^{\text {th }}, 2017$.

Published: . December $13^{\text {th }}, 2017$.

Copyright $\odot 2016$ by authors and Institute of Technology Galileo of Amazon (ITEGAM).This work is licensed under the CreativeCommons Attribution International License (CC BY 4.0) http://creativecommons.org/licenses/by/4.0/

\begin{abstract}
The use of tire scraping with the mortar has been the object of study today, with the purpose of reusing this material, transforming it from the use of civil construction. The aim of this article is to develop thermal and acoustic insulation boards, field test, compare with existing materials in the market, and analyze the prices in relation to these materials, with the purpose of valorizing the reuse of tire shavings in the city of Manaus / AM. The methodology is characterized as exploratory and qualitative, since the following materials were used: rubber scrap, cement, SIKA, water, white glue, polyvinyl chloride (PVC) pipe $20 \mathrm{~mm}$, sand, deform, insulation, PVC film. It is concluded that the volume of waste tires arriving in Manaus is large and does not yet have many options for the use of these tires other than burning, which is one of the difficulties found in the research.
\end{abstract}

Keywords: Insulation board. Thermoacoustic. Tire scraper.

\section{Estudo térmico: placas de isolações térmicas e acústicas}

\begin{abstract}
RESUMO
O uso da raspa de pneus junto à argamassa, tem sido objeto de estudo atualmente, com a finalidade de reaproveitar esse material transformando-o de uso da construção civil. O presente artigo tem como objetivo de desenvolver placas de isolações térmicas e acústicas, fazer teste em campo e comparar com materiais já existentes no mercado e analisar os preços em relação a esses materiais, com o intuito de valorizar o reaproveitamento de raspas de pneu na cidade de Manaus/AM. A metodologia é caracterizada como exploratória e qualitativa, visto que foram utilizados os materiais: raspas de borracha, cimento, SIKA, água, cola branca, tubo de Policloreto de Polivinila (PVC) 20 $\mathrm{mm}$, areia, desforme, isolantes, filme de PVC. Conclui-se que o volume de pneus inservíveis que chegam até Manaus é grande e ainda não tem muitas opções de uso desses pneus a não ser a queima, sendo esta uma das dificuldades encontradas na pesquisa.
\end{abstract}

Palavras-chave: Placa de isolamento. Termo acústico. Raspa de pneus.

\section{INTRODUÇÃO}

A descoberta da borracha vulcanizada em 1839 foi um marco na história dos pneus, com a necessidade de desenvolver um meio de transporte, mais rápido e adequado para o transporte de cargas e pessoas da época. A ideia surgiu dos irmãos Michelin que foram os primeiros a patentear o pneu. A borracha é de grande utilidade no mundo inteiro e principalmente usada de diversas maneiras, cada vez com técnicas mais apuradas. Atualmente esse assunto vem despertando o interesse de muitas empresas, que procuram achar uma saída para este problema, e a solução adequada seria a reutilização desses pneus, de certo modo possa diminuir o impacto que os mesmos causam ao meio ambiente quando descartados de forma inadequada.

Considerando os aspectos ambientais, sociais e econômicos e o grau de desenvolvimento tecnológico de cada solução, propondo-se encaminhamentos para cada um dos itens analisados, através de uma abordagem global, para viabilizar a implantação da comunidade, esta pesquisa possibilitou o uso de materiais com raspas de pneus.

Assim, a probabilidade de transformar o pneu destacado em material útil, com base no material utilizado tornaram-se fundamental para análise e são apresentadas alternativas às soluções adotadas, buscando-se o uso de técnicas 
autossustentáveis de baixo custo e acessíveis à população de baixa renda.

\section{MÉTODO PROPOSTO}

Este artigo consiste no desenvolvimento de uma placa de isolação térmica e acústica e fazer um comparativo com os outros materiais já existentes, em relação à funcionalidade e preços. Para se chegar à composição ideal foi necessária uma série de testes e análise em relação ao comportamento de cada material.

Vale ressaltar com a ajuda da empresa RIOLIMPO ${ }^{1}$ foi possível fazer uma coleta de dados necessários para a elaboração deste trabalho, pois a mesma forneceu a raspa de borracha de pneus provenientes do processo de recauchutagem de pneus. De acordo com [1] "o pneu é composto com diversos materiais, como aço, náilon, fibra de aramida, rayon, fibra de vidro/poliéster, borracha natural e sintética" [...].

\section{1 AS ETAPAS DOS TESTES COM A RASPA DE PNEU}

Nesse processo foi realizado quatro testes para a formação de uma placa de isolamento térmico e acústico. Observa-se o quadro abaixo destacando os materiais e métodos nesse processo:

Quadro 1: Materiais utilizados nos testes.

\begin{tabular}{|c|c|c|c|c|c|c|c|}
\hline Teste & $\begin{array}{c}\text { Areia } \\
\mathbf{k} / \mathbf{g}\end{array}$ & $\begin{array}{c}\text { Cimento } \\
\mathbf{k} / \mathbf{g}\end{array}$ & $\begin{array}{c}\text { Raspa } \\
\mathbf{k} / \mathbf{g}\end{array}$ & $\begin{array}{c}\text { Água } \\
\mathbf{k} / \mathbf{g}\end{array}$ & $\begin{array}{c}\text { Cola } \\
\text { branca }\end{array}$ & Canudos & $\begin{array}{c}\text { Aditivo } \\
\text { (vedalit) }\end{array}$ \\
\hline $\mathbf{\mathbf { 1 } ^ { \circ }}$ & $100 \mathrm{~g}$ & $100 \mathrm{~g}$ & $100 \mathrm{~g}$ & $100 \mathrm{~g}$ & - & - & - \\
\hline $\mathbf{2}^{\mathbf{0}}$ & $50 \mathrm{~g}$ & $30 \mathrm{~g}$ & $100 \mathrm{~g}$ & $15 \mathrm{~g}$ & $90 \mathrm{~g}$ & - & - \\
\hline $\mathbf{3}^{\mathbf{0}}$ & $120 \mathrm{~g}$ & $80 \mathrm{~g}$ & $150 \mathrm{~g}$ & $100 \mathrm{~g}$ & $35 \mathrm{~g}$ & 9 unid. & - \\
\hline $\mathbf{4}^{\circ}$ & $150 \mathrm{~g}$ & $120 \mathrm{~g}$ & $150 \mathrm{~g}$ & $100 \mathrm{~g}$ & - & $\begin{array}{c}10 \\
\text { unid. }\end{array}$ & $2 \mathrm{ml}$ \\
\hline
\end{tabular}

Fonte: Autores, (2017). a) $1^{\circ}$ teste

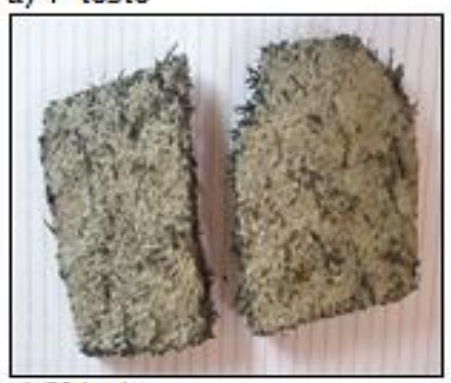

c) $3^{\circ}$ teste

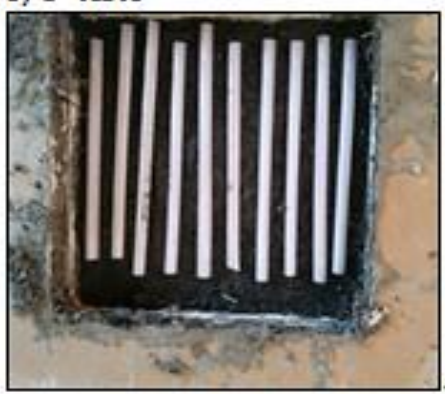

b) $2^{\circ}$ teste

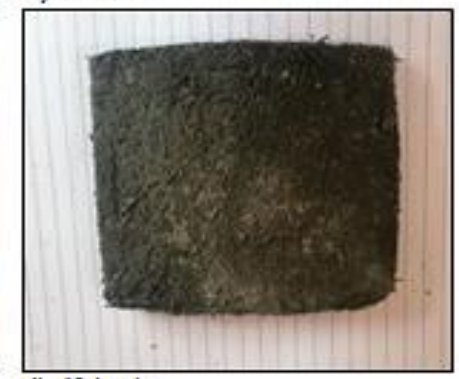

d) $4^{\circ}$ teste

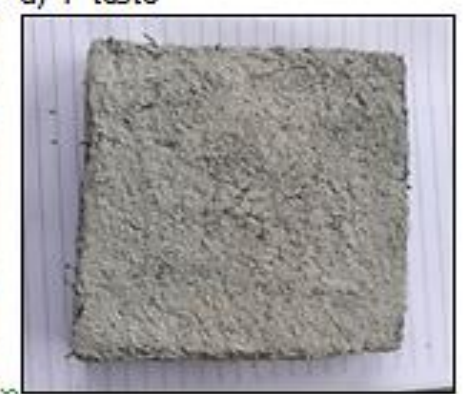

Figura 1: Demonstração dos testes com as raspas de pneu Fonte: Autores, (2017).

${ }^{1}$ Empresa localizada na cidade de Manaus que atua no mercado de reaproveitamento de sucatas tais como: papel, papelão, ferro, pneus entre outros.
A análise dos testes, com relação ao $1^{\circ}$ teste a placa não é muito eficiente, pois ficou muito compacta devido à quantidade de areia e os grânulos possuírem uma granulometria muito fina. Em relação ao custo, à quantidade significativa de cimento tornaria o material com preço elevado.

No $2^{\circ}$ teste, a placa embora muito compacta facilita a passagem de calor, deixando o material ineficiente. Em se tratando do "tempo de presa", é consideravelmente demorado, e apesar do baixo custo em relação aos materiais, ainda assim não é o mais indicado.

Já no $3^{\circ}$ teste, com os canudos no interior da placa dificulta a passagem de calor, porém, melhora a isolação térmica e acústica. No "tempo de presa" é razoavelmente demorado, mas dentro do planejado.

Por fim, no $4^{\circ}$ teste, com os canudos no interior da placa, este dificulta a passagem do calor, e melhora a isolação térmica e acústica. O “tempo de presa” é rápido, apesar da necessidade de mais tempo para inserir os canudos.

Conclui-se que os dois últimos testes são os mais indicados para a obtenção do material desejado. No que se refere ao ensaio de resistência à compressão, a normalização brasileira não prescreve nenhuma informação para o tema abordado.

Na tentativa de uma análise preliminar, adotou-se a NBR 7171/92 que trata sobre os Blocos Cerâmicos para Alvenaria, e dentro deste contexto, pode-se classificar as placas de vedação na classe $5 \mathrm{~cm}$, que prescreve que o referido material poderá ser empregado somente como painéis de vedação, vetando o seu uso como painéis estruturais.

Em relação ao material este poderá ser usado como material de vedação e emboço, diminuído assim, o custo em materiais e tempo. Vale ressaltar que existe vários estudos desse tipo de placas no mercado, mas são usados em: jardins, calçadas, decorações e em parques infantis. $\mathrm{Na}$ área da construção civil foram confeccionados: blocos de concreto com raspa de pneus, blocos pré-moldados como material de vedação (substituindo o tijolo), e estruturas com raspas de pneus e bambus. Sendo assim, [2] o processo de recauchutagem dos pneus é realizado por meio da raspagem das bandas de rodagem, dando origem aos resíduos de borracha de pneus, os quais se constituem de pequenas partículas com granulometria variável contendo inclusive partículas com dimensões em formato de fibras.

\section{II.2 O DESENVOLVIMENTO DAS PLACAS DE ISOLAÇÕES TÉRMICAS E ACÚSTICAS}

No desenvolvimento da confecção das placas de $50 \times 50 \times 0.5 \mathrm{~cm}$ foi necessário construir uma forma em madeira com furos com diâmetro de $20 \mathrm{~mm}$ para a sustentação dos canos e cada placa contendo 12 furos com distâncias de $1,5 \mathrm{~cm}$ entre cada furo.

$\mathrm{Na}$ base foi utilizado placas de porcelanato de 60x60 isolada com isolante para tubo e conexões, cada tubo (PVC) foi isolado com o mesmo isolante, cada haste da placa de madeira foi lixada e isolada com a finalidade do material pegar a presa ser fácil para soltar. Em consonância, realizou a confecção da placa em dois testes, utilizando-se os seguintes materiais:

Quadro 02: Materiais utilizados na confecção da placa

\begin{tabular}{|c|c|c|c|c|c|c|c|}
\hline Teste & $\begin{array}{c}\text { Areia } \\
\mathbf{k} / \mathbf{g}\end{array}$ & $\begin{array}{c}\text { Cimento } \\
\mathbf{k} / \mathbf{g}\end{array}$ & $\begin{array}{c}\text { Raspa } \\
\mathbf{k} / \mathbf{g}\end{array}$ & $\begin{array}{c}\text { Água } \\
\mathbf{k} / \mathbf{g}\end{array}$ & $\begin{array}{c}\text { Cola } \\
\text { bran } \\
\mathbf{c a}\end{array}$ & $\begin{array}{c}\text { Cano } \\
\mathbf{P V C} \\
\mathbf{2 0 m m}\end{array}$ & $\begin{array}{c}\text { Aditivo } \\
\text { (vedalit) }\end{array}$ \\
\hline $\mathbf{1} \mathbf{0}$ & $16 \mathrm{~kg}$ & $9 \mathrm{~kg}$ & $18 \mathrm{~kg}$ & $6 \mathrm{I}$ & $1 \mathrm{~kg}$ & $\begin{array}{l}48 \times 60 \mathrm{c} \\
\mathrm{m}\end{array}$ & $6 \mathrm{ml}$ \\
\hline $\mathbf{2} \mathbf{0}$ & $16 \mathrm{~kg}$ & $13 \mathrm{~kg}$ & $16 \mathrm{~kg}$ & $7 \mathrm{I}$ & $2 \mathrm{~kg}$ & $\begin{array}{l}48 \times 60 \mathrm{c} \\
\mathrm{m}\end{array}$ & $6 \mathrm{ml}$ \\
\hline
\end{tabular}

Fonte: Autores, 2017. 
Considerando o $1^{\circ}$ teste, o resultado não foi bem-sucedido em virtude da massa ter sido fraca e o isolante utilizado insuficiente, consequentemente não permitindo que as placas se soltassem das placas de porcelanatos, observa-se (Figura 2).

Nesse ínterim, a razão do fracasso do teste, é consequência da raspa ser composta por diversos tamanho, inclusive no pó que acaba alterando o peso específico do material. É importante destacar, uma vez encontrado o problema, foi utilizado a peneira de número $1.18 \mathrm{~mm}$, e o material que permaneceu retido nessa peneira tornar-se novamente aproveitado, sendo descartado aquele que passou pela peneira, e com relação ao "tempo de presa" este demorou em média dois dias.

Considerando o $1^{\circ}$ teste, o resultado não foi bem-sucedido em virtude da massa ter sido fraca e o isolante utilizado insuficiente, consequentemente não permitindo que as placas se soltassem das placas de porcelanatos, observa-se (Figura 2). Nesse ínterim, a razão do fracasso do teste, é consequência da raspa ser composta por diversos tamanho, inclusive no pó que acaba alterando o peso específico do material.

É importante destacar, uma vez encontrado o problema, foi utilizado a peneira de número $1.18 \mathrm{~mm}$, e o material que permaneceu retido nessa peneira tornar-se novamente aproveitado, sendo descartado aquele que passou pela peneira, e com relação ao "tempo de presa" este demorou em média dois dias.

No $2^{\circ}$ teste, foram confeccionadas novas placas, já lugar do isolante utilizou-se um filme plástico, tanto na base das placas de porcelanato quanto na forma de madeira e o isolante foi usado somente nos tubos PVC. Em consonância ao fracasso no $1^{\circ}$ teste, neste segundo processo tanto a quantidade e o material foram modificados. Sendo assim, resultado positivo, observa-se (Figura $3)$.

No $2^{\circ}$ teste, o "tempo de presa" de material ocorreu em 18 horas, permitindo a retirada dos tubos e em seguida das placas. Percebeu-se nesse momento que a placa apresentou boa resistência mecânica, e os materiais também apresentaram uma aderência excelente, mesmo após 24 horas ao ar livre e no sol.

Para verificar como o material suportaria a umidade, este foi molhado, e mesmo assim, verificou-se que as placas não apresentaram nenhuma modificação em relação a resistência ou a aderência dos materiais depois de ser molhado.

Segundo [3], os agregados reciclados de borracha de pneu são muito promissores na indústria da construção civil, devido às características inerentes a este material: leveza, elasticidade, absorção de energia, propriedades térmicas e acústicas.
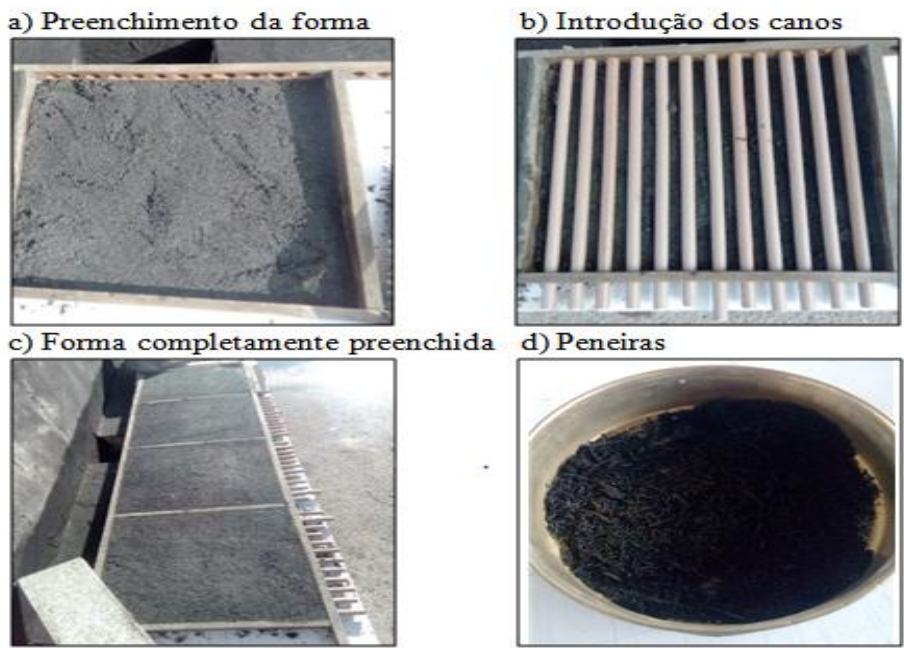

Figura 2: Demonstração do $1^{\circ}$ teste na construção das placas. Fonte: Autores, (2017).

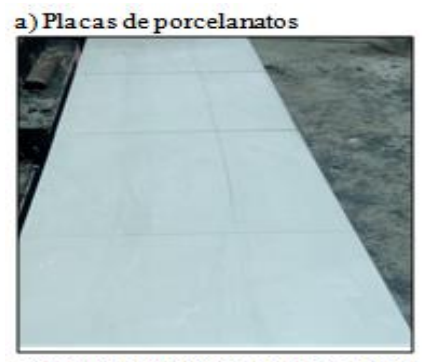

c) Forma completamente preenchida

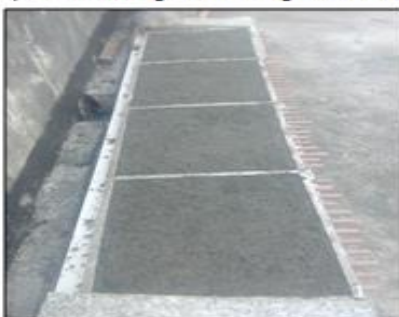

Figura 3: Demonstração do $2^{\circ}$ teste na construção das placas. Fonte: Autores, (2017).

\section{II.2.1 A CONSTRUÇÃO DAS CAIXAS COM RASPAS DE PNEUS}

No processo construtivo das placas com raspas de pneus, utilizou-se a construção de duas caixas de tamanhos 50x50x50 $\mathrm{cm}$ feitas com tijolos vazados de uso comum na construção civil, e com uma abertura de 22x $21 \mathrm{~cm}$, observa-se (Figura 4), sendo esta a entrada para o aparelho de medição. Possibilitando que as caixas fossem isoladas uma a uma a partir das placas feitas das raspas de pneus e a outra parte com placas de isopor, sendo ambas do mesmo tamanho e espessura, para a realização do comparativo de isolação termo acústico. Todas as operações de movimentação e colocação resultam significativamente encurtada [4].

Nessa perspectiva, todos os procedimentos realizados foram iguais para as duas caixas, ou seja, os mesmos materiais e técnicas. Outro fato importante no processo construtivo, destaca que na caixa com raspa de pneu, os espaços vazados foram levemente vedados para impedir a entrada de calor, sendo necessário, a utilização de mais uma placa para isolar o fundo da caixa, impedindo assim, a passagem de calor e ruído pelo fundo da caixa.
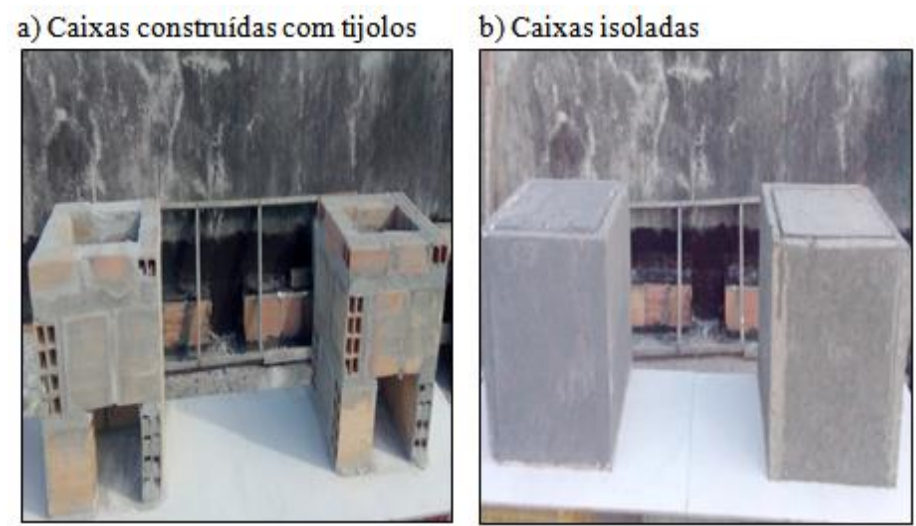

Figura 4: Processo construtivo das caixas com raspas de pneus Fonte: Autores, (2017).

\section{2.2 OS ENSAIOS COM AS PLACAS DE ISOLAÇÕES TÉRMICAS E ACÚSTICAS}

Na realização dos ensaios, observa-se no (Quadro 3), onde tem-se oito ensaios para verificar a isolação térmica e 
acústica, em consonância aos ensaios na (Figura 5), fica nítido o procedimento de casa ensaio.

Quadro 3: Os ensaios.

\begin{tabular}{|c|c|c|}
\hline Ensaio & $\begin{array}{l}\text { Material } \\
\text { utilizado }\end{array}$ & Procedimento \\
\hline $\begin{array}{l}\mathbf{1}^{\circ} \text { - Ensaio } \\
\text { de ruído } \\
\text { contínuo }\end{array}$ & $\begin{array}{l}\text { Aparelho } \\
\text { audiodosimetro } \\
\text { calibrado no } \\
\text { RBC/Inmetro }\end{array}$ & $\begin{array}{l}\text { Realizado na caixa de som, } \\
\text { usado dois audiodosimetro, } \\
\text { com filtro de banda, sendo um } \\
\text { dentro da caixa e outro fora da } \\
\text { caixa na mesma altura e } \\
\text { distância da caixa que emitia o } \\
\text { ruído. }\end{array}$ \\
\hline $\begin{array}{l}2^{\circ} \text { - Ensaio } \\
\text { de ruído de } \\
\text { impacto }\end{array}$ & $\begin{array}{l}\text { Barra de ferro } \\
3 \mathrm{~kg} \\
\text { Audiodosimetro }\end{array}$ & $\begin{array}{l}\text { Realizado em duas caixas, } \\
\text { onde foi lançado a barra de } \\
\text { ferro em uma altura de } 1 \mathrm{~m} \text { até } \\
\text { o piso repetido } 5 \text { vezes. }\end{array}$ \\
\hline $\begin{array}{l}3^{\circ} \text { - Ensaio } \\
\text { ruído de } \\
\text { atrito }\end{array}$ & $\begin{array}{c}\text { Enxada } \\
\text { Audiodosimetro }\end{array}$ & $\begin{array}{l}\text { Realizado em duas caixas, } \\
\text { onde a enxada foi utilizada } \\
\text { para produzir atrito sobre o } \\
\text { piso áspero com uma } \\
\text { frequência de } 5 \text { vezes. }\end{array}$ \\
\hline $\begin{array}{c}4^{\circ} \text { - Ensaio } \\
\text { de } \\
\text { temperatur } \\
\text { a }\end{array}$ & $\begin{array}{l}\text { Termômetro } \\
\text { globo e bubo } \\
\text { seco calibrado no } \\
\text { RBC/Inmetro }\end{array}$ & $\begin{array}{l}\text { O termômetro globo e bubo } \\
\text { seco foram colocados dentro } \\
\text { da caixa e fechado durante } 15 \\
\text { minutos, sendo realizado nas } \\
\text { duas caixas. }\end{array}$ \\
\hline $\begin{array}{l}5^{\circ} \text { - Ensaio } \\
\text { em relação } \\
\text { a incêndio }\end{array}$ & $\begin{array}{c}\text { Pedaço de placa } \\
\text { de raspa de pneu } \\
\text { e um pedaço de } \\
\text { isopor } \\
\text { embrulhados } \\
\text { com papel toalha }\end{array}$ & $\begin{array}{l}\text { Realizado o ensaio para fazer } \\
\text { um comparativo em relação ao } \\
\text { fogo, analisando o tempo e o } \\
\text { comportamento do material. }\end{array}$ \\
\hline $\begin{array}{c}6^{0} \text { - Ensaio } \\
\text { em relação } \\
\text { ao peso }\end{array}$ & $\begin{array}{l}\text { Placa de cimento } \\
\text { de } 3 \mathrm{~cm} \text { peso } \\
12.00 \mathrm{~kg} \\
\text { Placa de raspa de } \\
\text { pneu } 5 \mathrm{~cm} \mathrm{e} \\
20 \mathrm{~mm} \text { peso } \\
12.50 \mathrm{~kg}\end{array}$ & $\begin{array}{l}\text { Após confeccionado as duas } \\
\text { placas (cimento e raspas de } \\
\text { pneus), verificou-se que aplaca } \\
\text { com raspa de pneu é mais } \\
\text { pesada que a placa de cimento. }\end{array}$ \\
\hline $\begin{array}{l}7^{\circ} \text { - Ensaio } \\
\text { de } \\
\text { resistência }\end{array}$ & $\begin{array}{l}\text { Prensa hidráulica } \\
\text { Placa de raspa de } \\
\text { pneu } 5 \mathrm{~cm} \text { e placa } \\
\text { de cimento } 3 \mathrm{~cm}\end{array}$ & $\begin{array}{l}\text { Realizado com uma prensa } \\
\text { hidráulica com capacidade } \\
\text { para } 15 \text { toneladas, verificou-se } \\
\text { que a raspa de pneu tem menor } \\
\text { resistência do que a placa de } \\
\text { cimento. }\end{array}$ \\
\hline $\begin{array}{l}8^{\circ} \text { - Ensaio } \\
\text { de umidade }\end{array}$ & $\begin{array}{l}\text { Pedaço de placa } \\
\text { raspa de pneu }\end{array}$ & $\begin{array}{l}\text { A placa ficou completamente } \\
\text { imerso na água por } 15 \text { dias, } \\
\text { verificou-se que a placa não } \\
\text { sofreu alterações } \\
\text { significativas, em virtude da } \\
\text { composição do material ter } \\
\text { cola branca. }\end{array}$ \\
\hline
\end{tabular}

Fonte: Autores, (2017).
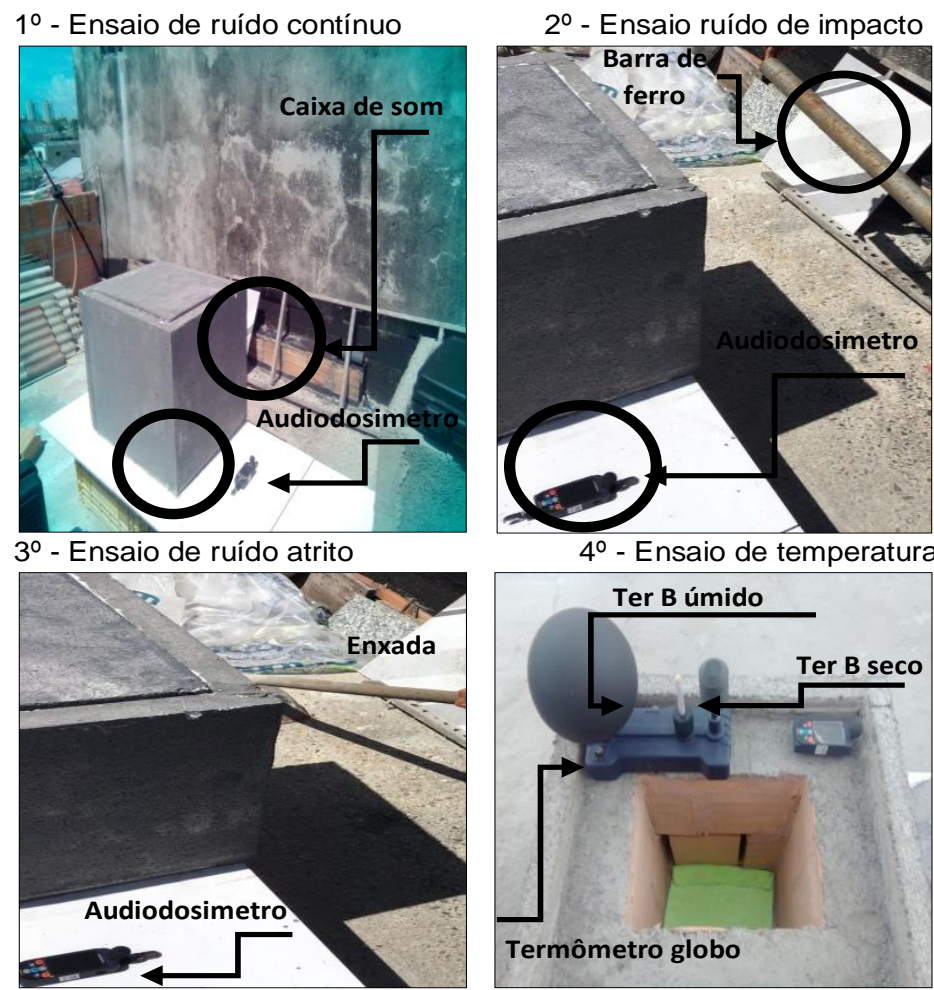

4ำ - Ensaio de temperatura
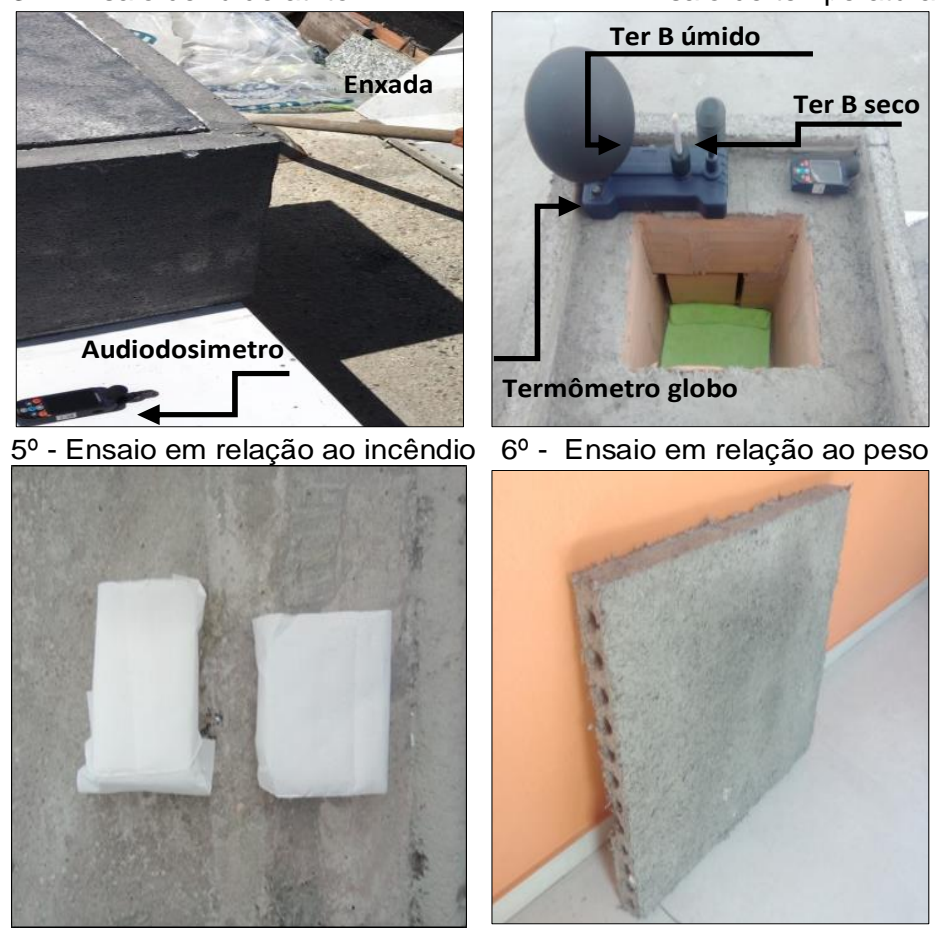

$7^{0}$ - Ensaio de resistência
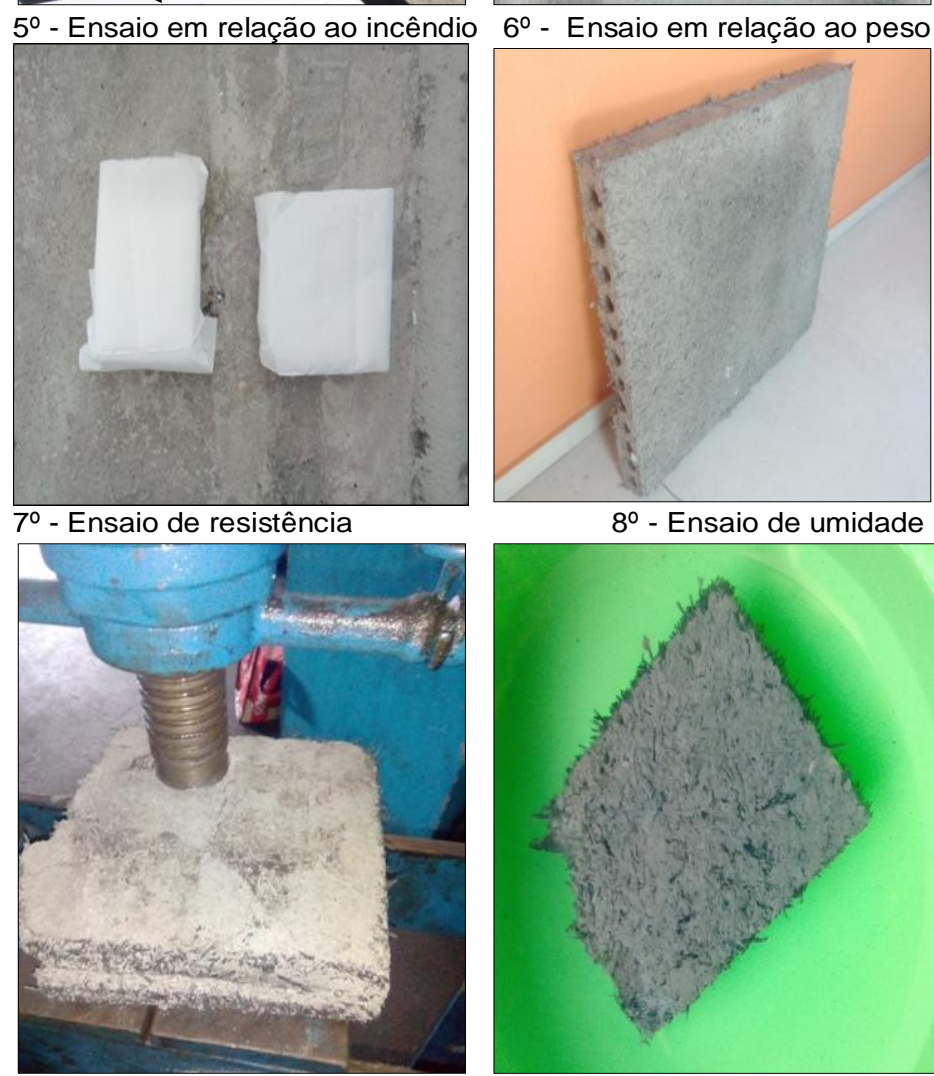

Figura 5: Demonstração dos ensaios com as placas de isolações térmicas e acústicas.

Fonte: Autores, (2017).

\section{2.3 COMPARATIVO DE PREÇOS}

Analisou-se no comparativo de preço, observa-se no (Quadro 4) foi realizado em relação ao preço dos materiais usados na composição da placa, vale ressaltar que isto não inclui a mão de obra e os equipamentos:

- $\quad 1 \mathrm{~m}^{2}$ da placa de isopor custa em média $\mathrm{R} \$ 23,00$;

- $\quad 1 \mathrm{~m}^{2}$ da placa feita com raspas de pneus custa em média $\mathrm{R} \$ 33,90$. 
O preço da placa foi calculado em relação aos preços dos materiais existente no mercado comprado em pouca quantidade.

Quadro 4: Preço do material para confecção da placa com raspa.

\begin{tabular}{|c|c|c|c|}
\hline $\begin{array}{c}\text { Descrição do } \\
\text { Material }\end{array}$ & $\begin{array}{c}\text { Preço do } \\
\text { Material }\end{array}$ & $\begin{array}{c}\text { Quantidade } \\
\text { do Material }\end{array}$ & $\begin{array}{c}\text { Preço do } \\
\text { Material } \\
\text { Utilizado }\end{array}$ \\
\hline $\begin{array}{c}\text { Raspas de } \\
\text { Pneu }\end{array}$ & $\mathrm{R} \$ 0,10$ & $16 \mathrm{~kg}$ & $\mathrm{R} \$ 1,60$ \\
\hline Cola Branca & $\mathrm{R} \$ 11,20$ & $2 \mathrm{~kg}$ & $\mathrm{R} \$ 22,40$ \\
\hline Vedalit & $\mathrm{R} \$ 9,00$ & $0,6 \mathrm{~kg}$ & $\mathrm{R} \$ 0,10$ \\
\hline Areia & $\mathrm{R} \$ 0,18$ & $16 \mathrm{~kg}$ & $\mathrm{R} \$ 2,88$ \\
\hline Cimento & $\mathrm{R} \$ 0,54$ & $13 \mathrm{~kg}$ & $\mathrm{R} \$ 7,00$ \\
\hline Água & $\mathrm{R} \$ 0,0$ & $7 \mathrm{~kg}$ & $\mathrm{R} \$ 0,00$ \\
\hline Valor Total & - & - & $\mathbf{R} \$ \mathbf{3 3 , 9 0}$ \\
\hline
\end{tabular}

Fonte: Autores, (2017).

\section{2.4 OS BENEFÍCIOS DAS PLACAS DE ISOLAÇÕES TÉRMICAS E ACÚSTICAS}

Os benefícios e vantagens encontrados na placa feita de raspas de pneus são:

- Resistente à umidade;

- Resistente a incêndio;

- Isolante térmico;

- Isolante acústico;

- Tem resistência necessária para ser utilizado como material de isolação; termo acústico;

- Pode ser utilizado como material revestimento como emboço;

- Contribui com a preservação do meio ambiente;

- Tem baixo custo;

- Fácil aplicação;

- Não transmite muita vibração.

\section{RESULTADOS E DISCUSSÃO}

Foram analisados, observa-se (Figuras - 5, 6 e 7) a avaliação do ruído fora das caixas; a avaliação do ruído dentro da caixa de isopor (Figuras - 8, 9 e 10) e, avaliação do ruído dentro da caixa com raspa de pneu (Figuras - 11, 12 e 13).

Os resultados do medidor de ruído, o LEQ deu um valor de 93,7 $\mathrm{dB}(\mathrm{A})$.

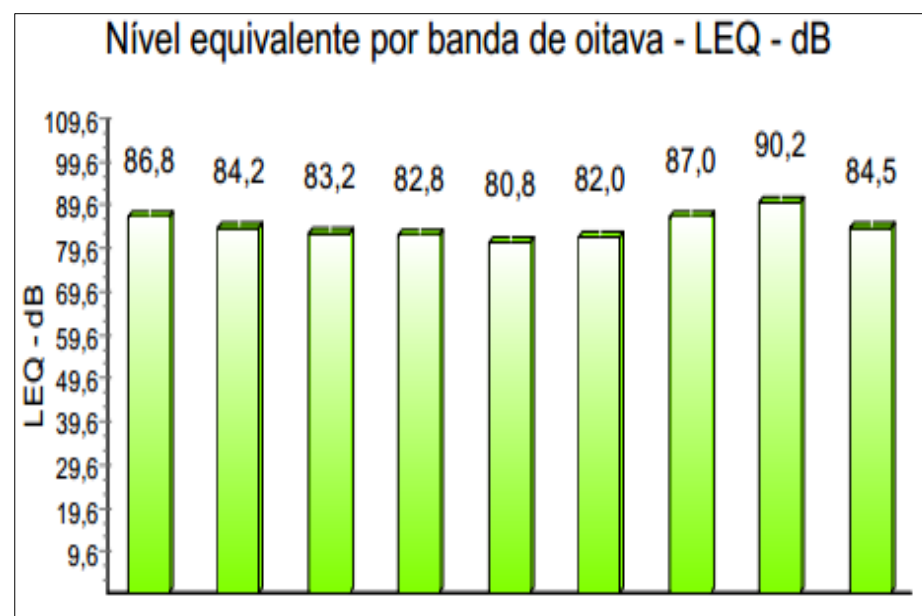

$31,5 \mathrm{~Hz} \quad 63 \mathrm{~Hz} 125 \mathrm{~Hz} 250 \mathrm{~Hz} 500 \mathrm{~Hz} \quad 1 \mathrm{kHz} \quad 2 \mathrm{kHz} \quad 4 \mathrm{kHz} \quad 8 \mathrm{kHz}$

Figura 5: Ruído fora da caixa sem ponderação

Fonte: Autores, (2017).
Nivel equivalente por banda de oitava ponderado - $\mathrm{LEQ}$ - dB(A)

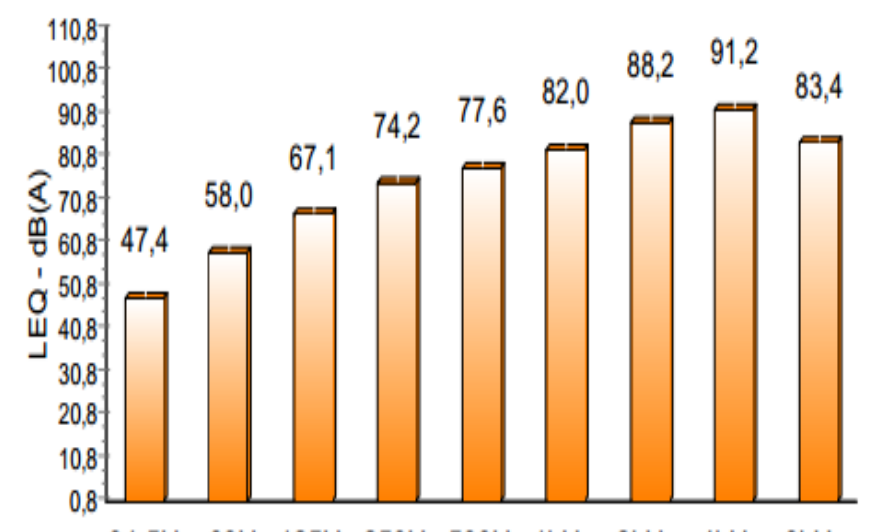

$31,5 \mathrm{~Hz} 63 \mathrm{~Hz} 125 \mathrm{~Hz} 250 \mathrm{~Hz} 500 \mathrm{~Hz} \quad 1 \mathrm{kHz} \quad 2 \mathrm{kHz} \quad 4 \mathrm{kHz} \quad 8 \mathrm{kHz}$

Figura 6: Ruído fora da caixa de isopor medido com medidor de ruído com filtro de banda oitava com curva de ponderação $\mathrm{A}$.

Fonte: Autores, (2017).

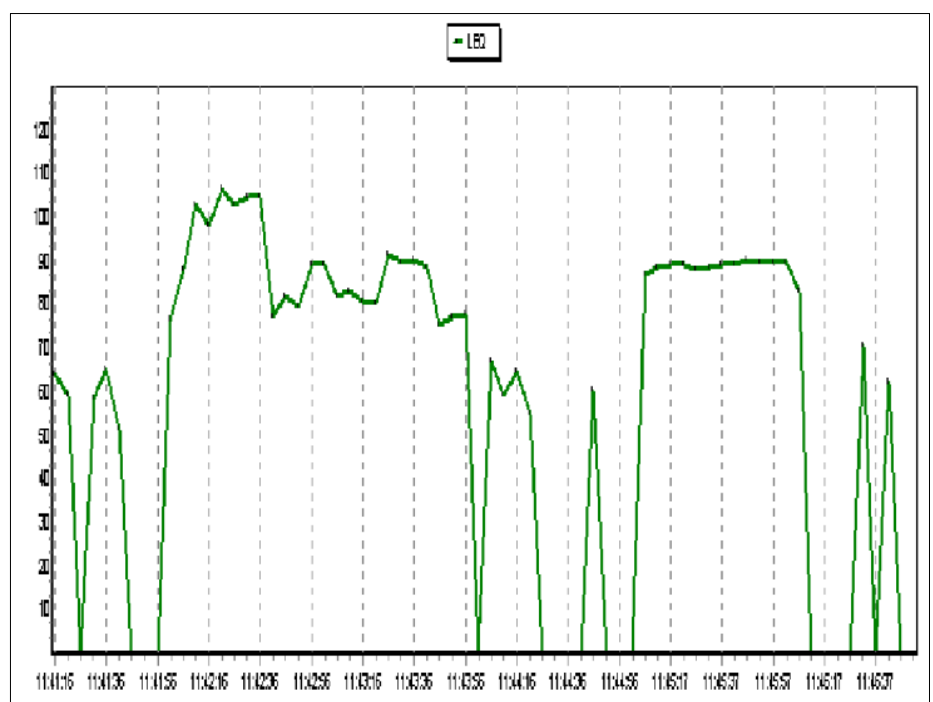

Figura 7: Histograma do ruído fora da caixa.

Fonte: Autores, (2017).

Os resultados do medidor de ruído, o LEQ deu um valor de $79,8 \mathrm{~dB}(\mathrm{~A})$.

\section{Nivel equivalente por banda de oitava - LEQ - $d B$}

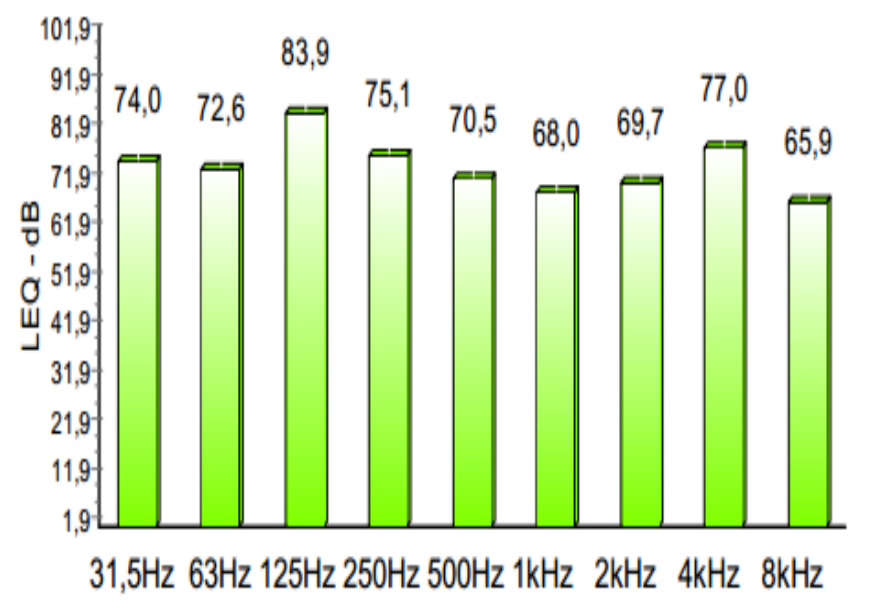

Figura 8: Ruído dentro da caixa de isopor sem ponderação.

Fonte: Autores, (2017). 


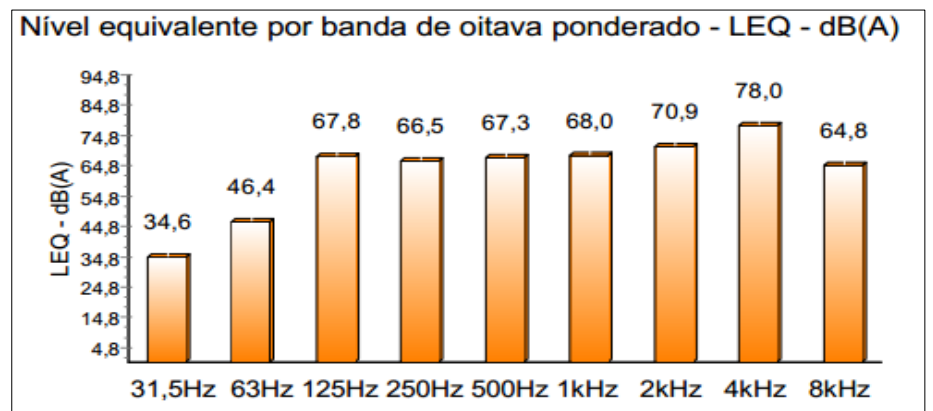

Figura 9: Ruído dentro da caixa de isopor medido com medidor de ruído com filtro de banda oitava com curva de ponderação A Fonte: Autores, (2017).

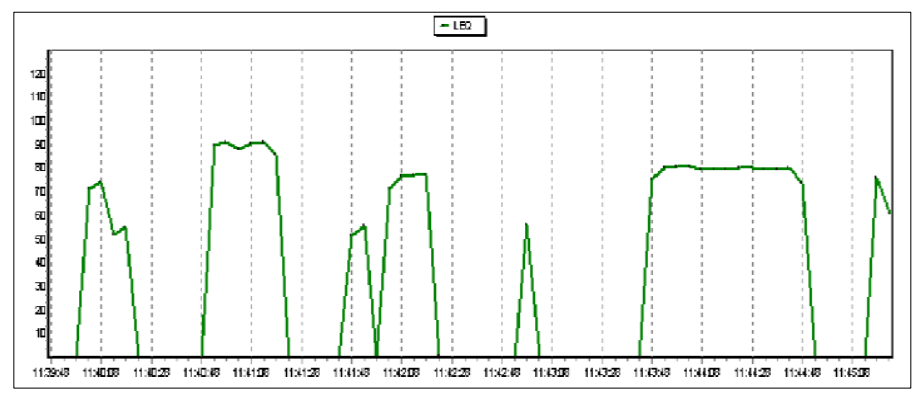

Figura 10: Histograma do ruído dentro da caixa de isopor.

Fonte: Autores, (2017).

Os resultados do medidor de ruído, o LEQ deu um valor de $74,6 \mathrm{~dB}(\mathrm{~A})$.

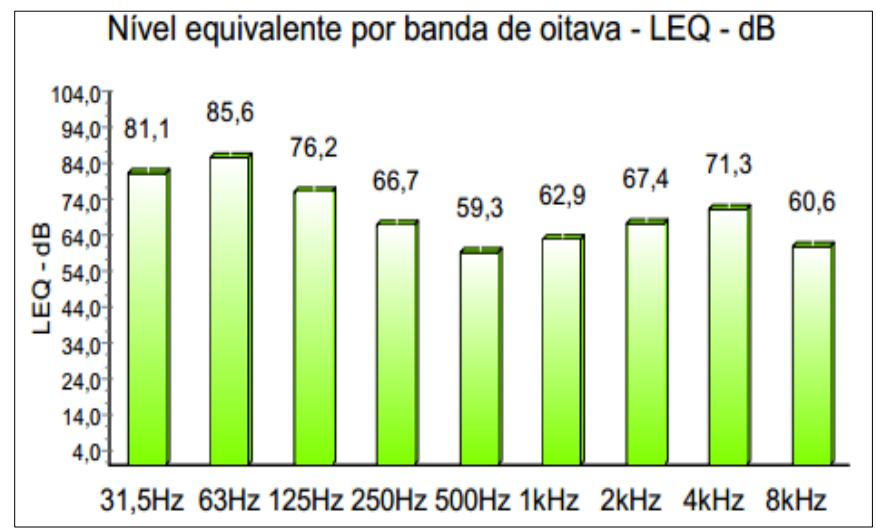

Figura 11: Ruído dentro da caixa com raspa de pneu sem ponderação.

Fonte: Autores, (2017).

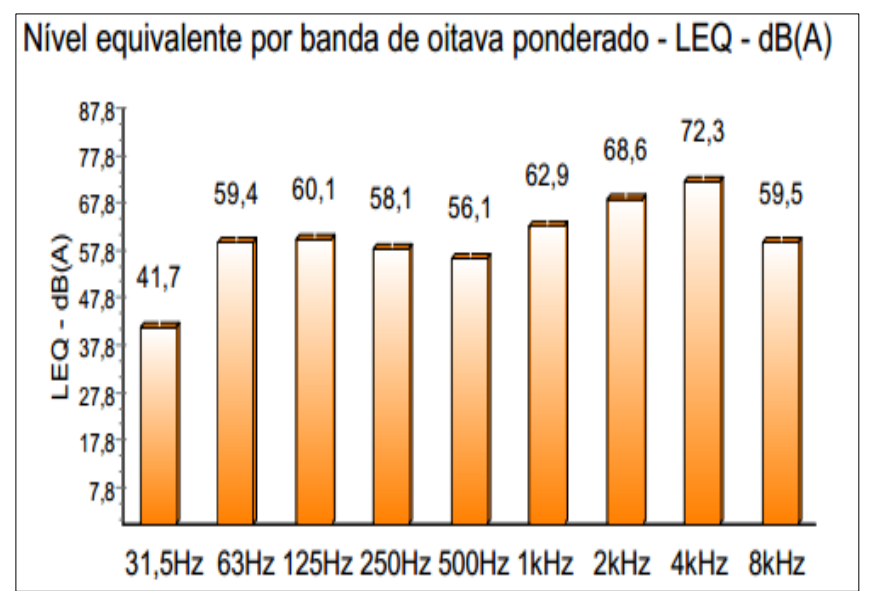

Figura 12: Ruído dentro da caixa com raspa de pneu com medidor de ruído com filtro de banda oitava com curva de ponderação A.

Fonte: Autores, (2017).

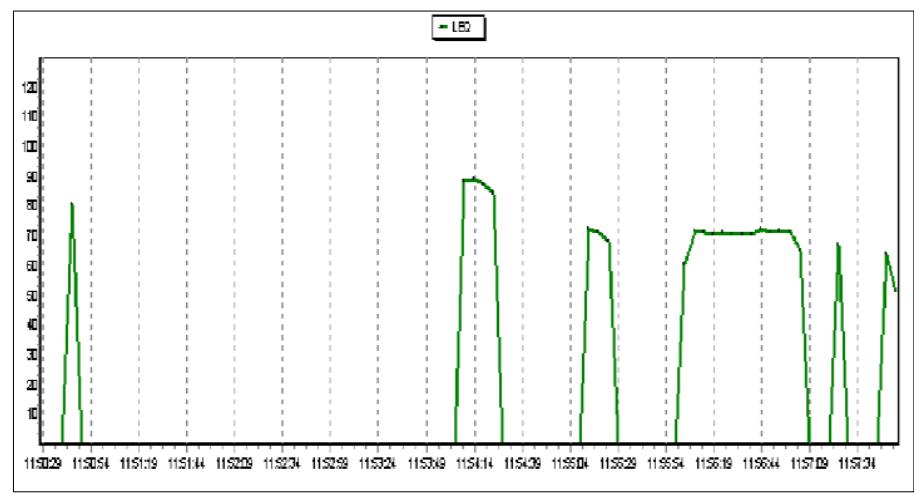

Figura 13: Histograma do ruído dentro da caixa com raspa de pneu. Fonte: Autores, (2017).

Analisando os resultados da avaliação do calor nas caixas, constatou-se:

- Medição da temperatura fora da caixa $38,7^{\circ} \mathrm{C}$

- Medição da temperatura dentro da caixa de isopor 34,1 ${ }^{\circ} \mathrm{C}$;

- Medição da temperatura dentro da caixa com raspas de pneu $33,0^{\circ} \mathrm{C}$.

Os ensaios de temperaturas foram realizados com termômetro globo, termômetro bubo seco e termômetro bubo úmido; todos os aparelhos foram calibrados no RBC/Inmetro.

\section{CONCLUSÃO}

Com base nos resultados apresentados em relação ao desempenho a ruído e ao calor é possível notar que a caixa com raspa de pneu teve um desempenho melhor em relação à caixa de isopor, logo que seus resultados foram mais eficientes. Em relação ao ensaio de incêndio a placa com raspas de pneu obteve melhor resultado uma vez que a placa continua com as mesmas características que antes do ensaio. No ensaio de compressão a placa com raspa de pneus apresentou menor resistência e maior elasticidade que a placa com cimento. Já no ensaio de umidade a placa obteve bom desempenho já que o material não sofreu nenhuma alteração.

Vale ressaltar que o tempo de durabilidade do material ainda não foi possível determinar, uma vez que as placas estão expostas ao sol e chuva por apenas 2 meses, e não apresentou nenhuma alteração.

Com base nos resultados é possível afirmar que há possibilidades de cria um material de isolação termo acústico com raspas de pneus e contribuir com a preservação do meio ambiente em relação ao destino final desse material. Por fim, o material apresenta grandes vantagens em relação a outros materiais de isolação térmica acústico. Por que, além de ser um material de isolação termo acústico também pode ser usado como material de emboço.

\section{REFERÊNCIAS}

[1] Bravo, Rafael Segantini. Análise de blocos de concreto com resíduo de borracha de pneu e metacaulim. 2014. 63 f. Dissertação (Mestrado) - Faculdade de Engenharia, Universidade Estadual Paulista, Ilha Solteira, 2014.

[2] Fioriti, C. F. Avaliação de compósitos de concreto com resíduos de borracha na produção de blocos para alvenaria. 2002. 134 f. Dissertação (Mestrado) - Faculdade de Engenharia, Universidade Estadual Paulista, Ilha Solteira, 2002. 
[3] Rodrigues, J. P. C.; SANTOS, C. C. Resistência à compressão a altas temperaturas do betão com agregados reciclados de borracha de pneu. In: CONGRESSO IBERO LATINO AMERICANO SOBRE SEGURANÇA CONTRA INCÊNDIO, 2, 2013, Coimbra. Anais... Coimbra: CILASCI, 2013.

[4] Silva, André da Rocha. Estudo térmico e de materiais na construção de casas populares co blocos confeccionados a partir de um composto a base de cimento, gesso, EPS e raspa de pneu. Dissertação de Mestrado. Universidade Federal do Rio Grande do Norte. Rio Grande do Norte, Natal, 2010. 